\title{
O Plano Nacional de Educação (2014-2024) e a garantia de um sistema educacional inclusivo: possibilidade ou utopia?
}

\section{Samuel Vinente \\ Márcia Duarte}

ReSumo: O texto discute as novas demandas do Plano Nacional de Educação - PNE (2014) para o Atendimento Educacional Especializado (AEE) de estudantes que compõem o Público-Alvo da Educação Especial (PAEE). Realizou-se uma análise documental com foco na meta 4 do PNE, sancionado por intermédio da Lei $n^{\circ} 13.005 / 2014$, e nas publicações do Ministério da Educação que norteiam sua implementação. Os dados evidenciam que, por mais que haja avanços no campo das políticas públicas, precisa-se de mecanismos que possibilitem a efetivação do direito do acesso e permanência na escola para os estudantes PAEE. Tais mecanismos sugerem: (a) criação e consolidação do Sistema Nacional de Educação; (b) análise dos indicadores educacionais do INEP, e; (c) avaliação e monitoramento dos planos estaduais e municipais. Portanto, implantar uma política decenal com vistas à garantia de um sistema educacional inclusivo requer planejamento, avaliação e monitoramento, bem como a participação efetiva dos entes federados e da sociedade civil.

Palavras-Chave: Educação Especial. Políticas Públicas. Plano Nacional de Educação.

\section{The National Education Plan (2014- 2024) and the guarantee of an inclusive educational system: possibility or utopia?}

AbSTRACT: The text discusses the new demands of Brazil's National Education Plan - PNE (2014) for specialized educational services for special education students. This study presents a documental analysis focused on the PNE goal \#4, sanctioned by means of Law $\mathrm{N}^{\circ} 13.005 / 2014$ and in the Ministry of Education's publications that guide the implementation. The data shows that while there are advances in the public policy, we still need to work on mechanisms to enable the actual right of access and permanence in school for special education students. Such mechanisms suggest: (a) the creation and consolidation of the National Education System; (b) analysis of the educational indicators from INEP and (c) assessment and monitoring of the state and city education plans. Therefore, implementing a ten-year policy that aims to ensure an inclusive education system requires planning, evaluation and monitoring, as well as the effective participation of federal entities and civil society.

Keywords: Special Education. Public Policies. National Education Plan. 
O Plano Nacional de Educação (2014-2024) e a garantia de um sistema educacional inclusivo: possibilidade ou utopia?

Samuel Vinente e Márcia Duarte

\section{Introdução}

A legislação educacional brasileira avançou no sentido de assegurar o acesso e a permanência de grande parcela da população na escola, mesmo com inúmeros desafios (CURY, 2002, 2005; DOURADO, 2007; DOURADO; OLIVEIRA, 2009; BUENO; MELETTI, 2012; SAVIANI, 2014a, 2014b). No entanto, a permanência e apropriação de conhecimentos dos estudantes Público-Alvo da Educação Especial ${ }^{1}$ (PAEE) na Educação Básica tem se mostrado, ainda, um desafio nos dias atuais (BRASIL, 2001, 2008; CURY, 2005; KASSAR; ARRUDA; BENATTI, 2011; BUENO; MELETTI, 2012; VINENTE; OLIVEIRA, 2014; VINENTE; DUARTE, 2015).

Recentemente, com a publicação do Plano Nacional de Educação (PNE), por meio da Lei ${ }^{\circ} 13.005$, de 25 de junho de 2014, garante-se na legislação educacional e projetase para a próxima década a universalização do atendimento escolar na Educação Básica, aos estudantes dos quatro (4) aos dezessete (17) anos. Dentre as dez diretrizes presentes no texto do PNE, propõe-se também a erradicação do analfabetismo, a superação das desigualdades educacionais e a universalização do atendimento escolar (BRASIL, 2014a).

$\mathrm{O}$ artigo $8^{\circ}$, parágrafo $1^{\circ}$, inciso III do PNE assegura que os entes federados deverão garantir em seus planos educacionais o atendimento às necessidades específicas da Educação Especial por meio de um sistema educacional inclusivo em todos os níveis, etapas e modalidades de ensino (BRASIL, 2014a). Sendo assim, problematizam-se, neste trabalho, os seguintes questionamentos: (1) a garantia desse sistema é uma possibilidade ou utopia, tendo em vista sua proposição em textos legais anteriores? (2) quais as implicações do atual PNE para o Atendimento Educacional Especializado (AEE) de estudantes PAEE? (3) como a sociedade civil pode articular-se para que o PNE seja implementado na prática?

No cerne da atual discussão, o trabalho objetiva analisar as políticas públicas relacionadas à inclusão escolar de estudantes PAEE, tendo como escopo de análise a meta 4 do PNE vigente, que trata sobre a universalização do acesso à Educação Básica e ao AEE de estudantes PAEE, preferencialmente na rede regular de ensino, “ [...] com a garantia de um sistema educacional inclusivo, de salas de recursos multifuncionais, classes, escolas ou serviços especializados, públicos ou conveniados" (BRASIL, 2014a, grifo nosso).

Levando-se em consideração a necessidade de problematizarmos questões sobre o PNE em consonância com a política educacional e a educação especial, o trabalho baseou-se num processo de análise por meio da pesquisa documental realizada no PNE e em dispositivos que consubstanciam as políticas de inclusão escolar. Segundo Gil

Compõem o grupo de estudantes Público-Alvo da Educação Especial (PAEE) alunos com deficiência, transtornos globais do desenvolvimento e altas habilidades ou superdotação, conforme previsto no artigo 58 da LDB (1996), por meio de redação dada pela Lei $\mathrm{n}^{\circ} 12.796 / 2013$. Esse grupo é representado atualmente nas pesquisas pela sigla PAEE, aparecendo inicialmente no $\operatorname{artigo~} 1^{\circ}$ do Decreto $n^{\circ} 7.611 / 2011$, que dispõe sobre a Educação Especial, o Atendimento Educacional Especializado e dá outras providências. Sendo assim, optamos por manter em todo o texto essa terminologia. 
O Plano Nacional de Educação (2014-2024) e a garantia de um sistema educacional inclusivo: possibilidade ou utopia?

Samuel Vinente e Márcia Duarte

(2008), esse tipo de pesquisa vale-se de materiais que não receberam ainda um tratamento analítico, ou que ainda podem ser reelaborados de acordo com os objetos da pesquisa.

O estudo vincula-se a uma pesquisa desenvolvida no Curso de Mestrado do Programa de Pós-Graduação em Educação Especial da Universidade Federal de São Carlos (UFSCar), com apoio da Fundação de Amparo à Pesquisa no Estado do Amazonas (FAPEAM), compondo o cronograma do Grupo de Estudos e Pesquisas sobre a Escolarização da Pessoa com Deficiência (GEPEPD).

\section{Aspectos históricos e legais do Plano Nacional de Educação}

O primeiro PNE surgiu no ano de 1962, elaborado ainda durante a vigência da primeira Lei de Diretrizes e Bases (LDB), a Lei nº 4.024/1961, de 20 de dezembro de 1961. O PNE foi proposto pelo Ministério da Educação (MEC), sendo aprovado na época pelo Conselho Federal de Educação (CFE).

A Lei $\mathrm{n}^{\circ}$ 5.692, de 11 de agosto de 1971, ao fixar as diretrizes e bases para o ensino de $1^{\circ}$ e $2^{\circ}$ graus, dispunha da assistência financeira aos Estados e Distrito Federal mediante a organização do sistema federal com caráter supletivo (BRASIL, 1971). Ao mesmo tempo em que se garantia na legislação da época planos nacionais de educação a serem estabelecidos, pouco se avançou no cenário educacional devido ao contexto histórico que assolava o país - o regime militar.

Após o período de redemocratização do Estado, em 1988, a Constituição Federal (CF) incitou a discussão sobre a formulação de um novo plano, "[...] com força de lei, capaz de conferir estabilidade às iniciativas governamentais na área de educação" (BRASIL, 2001). Em redação dada pela Emenda Constitucional no 59/2009, o artigo 214 da CF prevê que:

A lei estabelecerá o plano nacional de educação, de duração decenal, com o objetivo de articular o sistema nacional de educação em regime de colaboração e definir diretrizes, objetivos, metas e estratégias de implementação para assegurar a manutenção e desenvolvimento do ensino em seus diversos níveis, etapas e modalidades por meio de ações integradas dos poderes públicos das diferentes esferas federativas. (BRASIL, 1988, art. 214, n.p.)

No entanto, passaram-se alguns anos até que a promulgação desse plano fosse efetivada, mesmo já estando previsto na legislação anteriormente. A LDB, promulgada por meio da Lei Darcy Ribeiro $\mathrm{n}^{\circ}$ 9.394/1996, no artigo $9^{\circ}$, reiterou que caberia à União elaborar o PNE, em colaboração com os Estados, o Distrito Federal e os Municípios (BRASIL, 1996). Nos artigos 10 e 11 dessa mesma Lei, ficou definido que os Estados e Municípios elaborariam seus planos educacionais em consonância com as diretrizes e planos da União.

Após ser aprovado pelo Congresso Nacional e sancionado mediante a Lei $\mathrm{n}^{\circ}$ 10.172/2001, o PNE (BRASIL, 2001) entrou em vigor com os seguintes objetivos e 
O Plano Nacional de Educação (2014-2024) e a garantia de um sistema educacional inclusivo: possibilidade ou utopia?

prioridades: (a) elevação global do nível da escolaridade da população; (b) melhoria da qualidade do ensino em todos os níveis; (c) redução das desigualdades sociais e regionais no tocante ao acesso e permanência na escola; e (d) democratização da gestão do ensino público (BRASIL, 2001).

No entanto, pode-se perceber que poucos foram os avanços para o cumprimento das metas do PNE anterior. Dez anos não seriam ainda suficientes para que o Estado pagasse uma dívida histórica a uma grande parcela da população brasileira, excluída da escola ao longo de quinhentos anos. Ainda assim, algumas metas foram incorporadas ao texto da lei, visando assegurar a universalização do ensino principalmente para o Ensino Fundamental ${ }^{2}$.

Buscando atender às novas demandas sociais, o PNE (BRASIL, 2001) avançou ao promover, mesmo que no âmbito documental, o direito de acesso à escola e permanência na mesma, principalmente no tocante aos estudantes PAEE. O reconhecimento da diferença e a busca de mecanismos para o atendimento da diversidade humana protagonizou belos discursos no âmbito do PNE anterior.

Por incorporar demandas da Declaração Mundial sobre Educação para Todos, resultante de uma conferência mundial realizada na Tailândia, o PNE anterior atendia aos acordos internacionais do qual o Brasil tornou-se signatário. Previa-se no texto legal a adequação do espaço escolar, dos equipamentos e dos recursos. Falava-se também de uma escola aberta à diversidade e que contemplasse a participação da comunidade escolar.

No que se referia ao AEE de estudantes PAEE, predominavam as classes e as escolas especiais. Orientava-se na lei que as escolas especiais prestariam apoio aos programas de integração, em colaboração com o poder público. Sendo assim, recomendava-se a "[...] celebração de convênios intermunicipais e com organizações não-governamentais, para garantir o atendimento da clientela". (BRASIL, 2001, n.p.).

Já se propunha no texto anterior do PNE que as escolas especiais atendessem apenas estudantes com graus de deficiência mais severos. Apontava-se para uma preocupação na oferta dos serviços de Educação Especial em razão do diagnóstico realizado a partir dos dados do Instituto Nacional de Estudos e Pesquisas Educacionais Anísio Teixeira (INEP). Tais dados anunciavam que 59,1\% dos municípios brasileiros não ofereciam serviços de Educação Especial para os estudantes PAEE (BRASIL, 2001). Para minimizar a ausência de ações do Poder Público junto a esses estudantes, normatizou-se no PNE a celebração de convênios com vistas à oferta do AEE.

O PNE (2001) previa 28 objetivos e metas para a modalidade de Educação Especial, a serem cumpridas num total de dez anos. Dentre elas pode-se destacar: (a) oferta de estimulação precoce; (b) formação de professores da Educação Infantil e Ensino Médio para atendimento desse público; (c) aplicação de testes de acuidade visual/auditiva em todas as instituições de Educação Infantil e Ensino Fundamental; (d) criação de classes

\footnotetext{
Tal ênfase dada ao Ensino Fundamental se devia principalmente pela obrigatoriedade do Ensino Fundamental passam a ser estendidas também ao Ensino Médio e à parte da Educação Infantil, conforme Emenda Constitucional no 59/2009 (altera a redação da CF) e Lei no 12.796/2013 (altera a redação da LDB).
} 
O Plano Nacional de Educação (2014-2024) e a garantia de um sistema educacional inclusivo: possibilidade ou utopia?

Samuel Vinente e Márcia Duarte

especiais, salas de recursos e outros espaços para o $\mathrm{AEE}^{3}$; (e) disponibilização de livros didáticos falados, em Braille e caracteres ampliados para alunos cegos e com baixa visão, dentre outros (BRASIL, 2001).

Na perspectiva de Cury (2005), "É do reconhecimento da igualdade essencial de todos os indivíduos da espécie humana que se nutriram as teses dos direitos universais da pessoa humana e, por decorrência, as teorias da cidadania, da democracia [...]" (CURY, 2005, p. 59). Sendo assim, a mobilização em torno de um plano que contemple as diferenças é crucial para que se garantam direitos inerentes e sejam possibilitadas oportunidades de aprendizagem aos estudantes PAEE.

\section{Plano Nacional de Educação (2014): demandas e perspectivas atuais}

A legitimação de um plano educacional com período decenal deve ser entendida como uma política de Estado, devendo ser efetivada com a participação intensiva dos entes federados e da sociedade civil (AGUIAR, 2010; OLIVEIRA, 2011; OLIVEIRA, et al, 2011; SAVIANI, 2014a; 2014b). As políticas de Estado são traduzidas por Oliveira (2011) como políticas que envolvem mais de uma agência de Estado, passando em geral pelo Parlamento ou por instâncias diversas de discussão, resultando em mudanças de outras normas ou dispositivos já existentes, tendo sua incidência em setores sociais mais amplos.

Ao realizarem análise dos documentos preparatórios para o PNE, Laplane e Prieto (2010) apontam que durante a última década houve o aumento da visibilidade de temas relativos a inclusão, refletindo então nas discussões anteriores à aprovação do plano uma “[...] presença maciça na formulação de princípios e metas educacionais para a próxima década" (LAPLANE; PRIETO, 2010, p. 919).

Após longa discussão no Congresso Nacional e nos demais fóruns de discussão, o PNE atual (2014) foi sancionado por meio de lei três anos após o encerramento da vigência do plano anterior. Ou seja, o Brasil ficou anos sem nenhum plano nacional que dispusesse de normas e estratégias para a educação nacional, o que denunciou a falta de vontade política na institucionalização de um plano que atendesse aos interesses da população e dos inúmeros movimentos sociais (VINENTE; DUARTE, 2015).

O contexto de aprovação e publicação do texto do PNE foi o ano de 2014, ano em que houve a corrida eleitoral aos cargos de presidente da República, senadores, deputados federais e estaduais e governadores de Estado. O plano apresenta diversas diretrizes, um total de dez, presentes no artigo $2^{\circ}$, incisos de I a X, os quais elencamos: (a) erradicação do analfabetismo; (b) universalização do atendimento escolar; (c) superação das desigualdades educacionais; (d) melhoria da qualidade da educação; (e) promoção do

\footnotetext{
$\mathrm{O}$ atendimento educacional especializado (AEE) é o conjunto de atividades, recursos de acessibilidade e pedagógicos organizados institucional e continuamente, que pode ser prestado de forma complementar (aos educandos com deficiência e transtornos globais do desenvolvimento) ou suplementar (aos educandos com altas habilidades ou superdotação), vide Decreto $n^{\circ} 7.611 / 2011$.
} 
O Plano Nacional de Educação (2014-2024) e a garantia de um sistema educacional inclusivo: possibilidade ou utopia?

Samuel Vinente e Márcia Duarte

princípio da gestão democrática da educação pública; (f) promoção dos princípios do respeito aos direitos humanos, entre outros (BRASIL, 2014a).

Diferentemente do plano anterior, o atual PNE estabelece dez diretrizes que norteiam as ações a serem executadas e vinte metas a serem implementadas por meio de estratégias. Destacam-se no texto as seguintes metas: (a) universalização da Educação Infantil na etapa da pré-escola; (b) universalização do Ensino Fundamental; (c) universalização do Ensino Médio; (d) alfabetização de todas as crianças até o final do $3^{\circ}$ ano do Ensino Fundamental; (e) educação em tempo integral; (f) alcance dos índices mínimos do IDEB; (g) elevação da taxa de alfabetização da população brasileira, dentre outras (BRASIL, 2014a, grifo nosso).

O artigo $4^{\circ}$ delega ao Ministério da Educação (MEC), ao Conselho Nacional de Educação (CNE), ao Fórum Mundial de Educação e às Comissões de Educação da Câmara dos Deputados e do Senado Federal o monitoramento contínuo e a avaliação do atual PNE. Garante-se na lei que o plano plurianual, as diretrizes orçamentárias e os orçamentos anuais dos entes federados sejam reformulados a fim de que viabilizem as metas e estratégias do plano (BRASIL, 2014a).

Quanto ao AEE, o artigo $8^{\circ}$, parágrafo $1^{\circ}$, inciso III, normatiza que se deve garantir o atendimento das necessidades específicas na Educação Especial, assegurando um sistema educacional inclusivo em todos os níveis, etapas e modalidades, bem como a articulação interfederativa na implementação das políticas educacionais (BRASIL, 2014a). Mais uma vez a legislação delineia a Educação Especial como transversal aos níveis (Educação Básica e Superior), etapas (Educação Infantil, Ensinos Fundamental e Médio) e modalidades de ensino (Educação de Jovens e Adultos, Educação Profissional, Educação Escolar Indígena, Educação a Distância).

Vinente et al. (2014) ao analisarem os dispositivos do novo PNE alertam que apesar do objetivo de "universalizar" o atendimento escolar aos estudantes PAEE, as estratégias para tal universalização não estariam claramente definidas. Para os autores, o principal debate em torno da meta 4 seria a coexistência dos setores público e privado na oferta do AEE.

A parceria público/privado tem sido recorrente desde a década de 1990 na legislação educacional brasileira, sendo inerente ao atual modelo econômico em vigência no Brasil. Para Garcia e Michels (2011), “[...] a reforma do Estado brasileiro na década de 1990 favoreceu uma situação que já estava naturalizada para a Educação Especial, qual seja a relação público/privado na execução do atendimento educacional" (GARCIA; MICHELS, 2011, p. 110).

A meta quatro (4) do PNE propõe a universalização da escola, para a população PAEE de quatro (4) a dezessete (17) anos, bem como o AEE preferencialmente na rede regular de ensino, com a garantia de sistema educacional inclusivo, de salas de recursos multifuncionais, classes, escolas ou serviços especializados, públicos ou conveniados. 
O Plano Nacional de Educação (2014-2024) e a garantia de um sistema educacional inclusivo: possibilidade ou utopia?

No texto da lei há a possibilidade desse atendimento em diferentes espaços e em parceria com as instituições. Corroborando com o estudo de Kassar, Arruda e Benatti (2011) sobre as políticas de inclusão escolar, entendemos que a "[...] presença das instituições tem sido em parte financiada pelo Estado e sustentada pela legislação" (KASSAR; ARRUDA; BENATTI, 2011, p. 25).

Embora possa afirmar-se que houve poucas modificações no que se refere à forma de oferta do AEE do plano anterior (BRASIL, 2001) ao plano atual (BRASIL, 2014), a intensa mobilização dos diversos segmentos da sociedade quanto à manutenção ou extinção das instituições que ofertavam os serviços de Educação Especial garantiu uma correlação de forças, na qual é enfraquecida a concepção de inclusão total ${ }^{5}$ adotada pelo MEC para implementação da política de Educação Especial.

Nesse contexto, levando-se em consideração a intensa polêmica que envolve a escolarização dos estudantes que compõem o PAEE, a concepção de inclusão total perde forças no novo PNE e garante outras formas na organização do AEE e mesmo na constituição dos serviços de Educação Especial.

A Nota Técnica $\mathrm{n}^{\circ}$ 108/2013, de 21 de agosto de 2013, referente à meta 4 do PNE, emitida pelo MEC, estabelece que a Educação Especial deixa de ser um sistema paralelo e segregacionista de ensino, passando a ser estabelecido como modalidade que possui função complementar (BRASIL, 2013). O documento informava a posição do MEC, contrária ao que este denominava um "equívoco conceitual" sobre o emprego do termo "preferencialmente" no substitutivo aprovado na Câmara dos Deputados, referindo-se ao acesso à educação regular.

Mesmo com o amplo debate que se estabeleceu na época, o texto aprovado e publicado manteve a meta de universalização do AEE aos estudantes "preferencialmente na rede regular de ensino", garantindo-se também a oferta desse serviço em "[...] salas de recursos multifuncionais, classes, escolas ou serviços especializados, públicos ou conveniados" (BRASIL, 2014a, n.p.).

Para o cumprimento da meta foram propostas dezenove (19) estratégias, das quais destacamos: (a) oferta da educação bilíngue; (b) repasse financeiro às escolas públicas e instituições especializadas; (c) implantação de salas de recursos multifuncionais; (d) formação de professores para o AEE; (e) manutenção e ampliação de programas suplementares, entre outras.

\footnotetext{
${ }^{4}$ Em 2001 o PNE organizava as formas de atendimento educacional por meio da participação dos alunos nas: (a) salas comuns; (b) salas de recursos; e, (c) salas e escolas especiais. No atual plano, mantém-se quase a mesma estrutura alterando os termos para salas de recursos multifuncionais, classes, escolas e serviços especializados, podendo ser públicos ou conveniados. (BRASIL, 2014).

O termo full inclusion (Gartner; Lipsky, 1989; Stainback; Stainback, 1984 in MENDES, 2006) é traduzido como inclusão total por Mendes (2006) e representa uma concepção de política de inclusão que compreende a matrícula de todos os estudantes com deficiência no sistema regular de ensino.
} 
O Plano Nacional de Educação (2014-2024) e a garantia de um sistema educacional inclusivo: possibilidade ou utopia?

Pode-se dizer que só o fato de se propor universalização do acesso à escola para esse público-alvo já soa como uma utopia ${ }^{6}$, tendo em vista que muitos alunos que não integram esse grupo ainda estão excluídos do processo de escolarização (CURY, 2005 VINENTE; OLIVEIRA, 2014; SAVIANI, 2014a; SAVIANI, 2014b; VINENTE; DUARTE, 2015). Além disso, torna-se necessário criar mecanismos sólidos para que se implemente uma universalização do atendimento desse público em apenas dez (10) anos.

Para Laplane e Prieto (2010), “[...] o novo Plano Nacional de Educação terá como tarefas principais articular as reivindicações dos grupos historicamente preteridos, de modo a integrar os esforços na direção de atender às suas particularidades, sem pulverizar recursos e duplicar ações" (LAPLANE; PRIETO, 2010, p. 939).

Sendo assim, conforme o texto da lei pode ser que haja uma prioridade na oferta da Educação Infantil e do Ensino Médio em virtude das modificações que ocorreram na legislação, tendo em vista que, na última década, deu-se preferência ao Ensino Fundamental.

Com a extensão da obrigatoriedade e gratuidade da Educação Básica pelo Poder Público por meio das alterações na CF (BRASIL, 1988) e na LDB (BRASIL, 1996), parte da Educação Infantil (pré-escola) passa a ser compreendida como "direito público e subjetivo". Será um desafio planejar a oferta de serviços para o suporte à inclusão escolar e a garantir a matrícula das crianças pequenas nos estabelecimentos públicos de ensino.

Além disso, pretende-se fomentar a oferta desse atendimento ao PAEE, visando oferecer assegurar a educação bilíngue para crianças surdas e a transversalidade da Educação Especial nos diferentes níveis e modalidades de ensino, preferencialmente na Educação Básica (BRASIL, 2014a). Será necessário implantar salas de recursos multifuncionais e outros serviços de educação especial na Educação Infantil, bem como consolidar a formação dos professores que atuam nessa etapa de ensino. Essas novas demandas trarão à tona a necessidade de estudos que visem avaliar a execução das diversas estratégias referentes à meta 4.

Se o MEC vem adotando há algum tempo a implantação das salas de recursos multifuncionais no país, o PNE (2014) intensifica que haverá maior fomento à expansão dessas salas e formação continuada de professores para o AEE, tanto nas escolas urbanas, como nas escolas do campo, indígenas e de comunidades quilombolas (BRASIL, 2014a).

Acredita-se, no entanto, que são necessários mais estudos no campo das políticas educacionais visando verificar o cumprimento dessa estratégia proposta no referido plano, no sentido de monitorar a implementação das políticas públicas para o atendimento desse público.

\footnotetext{
Os autores concebem utopia não como atividade irrealizável, mas como incerto e longínquo. Nessa perspectiva, não concebemos a garantia de um sistema educacional inclusivo como incerta, pois projeta-se para a próxima década metas e estratégias com força de lei. Entretanto, quando o legislador aponta como diretriz a universalização no prazo exposto cabe aí problematizar a necessidade de intensa participação dos entes federados para que se avance na garantia de um sistema educacional inclusivo.
} 


\section{Por uma avaliação e monitoramento do PNE: o sistema educacional inclusivo em questão}

Ao menos no discurso do Governo Federal em vigência, a educação entrou em pauta. O atual lema, intitulado "Brasil: pátria educadora", busca atender aos anseios dos movimentos sociais e políticos que ao longo dos últimos anos vêm ganhando espaço, desde a mobilização nacional por parte dos recursos provenientes da exploração da reserva petrolífera do Pré-Sal (reserva petrolífera explorada pela Petrobrás com produção abundante) à representação nos diversos fóruns de discussão sobre políticas educacionais. $\mathrm{O}$ artigo $5^{\circ}$ do PNE prevê a destinação de parcela do recurso para manutenção e desenvolvimento do ensino, visando cumprir a meta prevista no inciso IV, do artigo 214 da CF (BRASIL, 2014a).

Avançou-se também na democratização do acesso à escola e na criação de programas de transferência de renda, moradia, alimentação, estruturação das universidades e expansão das matrículas em todos os níveis de ensino. Em nenhum momento pode-se analisar a atual conjuntura como algo dependente apenas das ações de um partido político ou da esquerda ter assumido o poder, mas sim do avanço no campo das políticas sociais já garantidos desde a Constituição Federal (BRASIL, 1988), demandas essas, que aos poucos, vêm se efetivando (CURY, 2002, 2005; DOURADO; OLIVEIRA, 2009; SAVIANI, 2014b; VINENTE; OLIVEIRA, 2014; VINENTE; DUARTE, 2015).

Se os termos sistema educacional inclusivo encontram-se presentes nos dispositivos jurídicos há algum tempo, é necessário criar mecanismos para que essas palavras não se consolidem como utopia, mas como possibilidade para que a escola seja cada vez mais enriquecida com a diversidade humana. Podem-se apontar três elementos imprescindíveis para que um dia alcancemos um sistema educacional inclusivo, a serem tratados a seguir: (1) a criação e consolidação do SNE; (2) a análise dos indicadores educacionais do INEP; e (3) a avaliação e o monitoramento dos planos estaduais e municipais de educação.

\subsection{A criação e consolidação do Sistema Nacional de Educação (SNE)}

As discussões sobre o Sistema Nacional de Educação (SNE), a ser instituído pelo PNE, não são recentes. A Constituição Federal (BRASIL, 1988) já previa em seu artigo 214 esse sistema, de modo que se garantisse a execução das metas e estratégias do PNE para que se alcançasse os princípios estabelecidos pelo plano.

Saviani (2012) já nos alertava sobre o uso inadequado do termo sistema, no qual o autor incitava a sociedade a discutir sobre a ausência de "[...] uma reflexão mais demorada sobre a noção de sistema educacional e sua utilização no quadro da educação brasileira” (SAVIANI, 2012, p. 13). Para o autor, “[...] o sistema não é um dado natural, mas é sempre um produto da ação humana" (SAVIANI, 2014b, p. 1). Sendo assim, o "sistema" seria o resultado do amplo processo de "sistematização", que exige dos entes federados e da sociedade civil uma ampla reflexão. 
O Plano Nacional de Educação (2014-2024) e a garantia de um sistema educacional inclusivo: possibilidade ou utopia?

Samuel Vinente e Márcia Duarte

O sistema é definido pelo autor como "[...] unidade de vários elementos intencionalmente reunidos de modo que forme um conjunto coerente e operante" (SAVIANI, 2014b, p. 4). Portanto, o sistema nasce da tomada de consciência sobre a realidade educacional do país, constituindo-se como alternativa para a superação dos problemas educacionais.

Pode-se considerar-se um avanço a inserção do SNE na pauta do PNE, pois o plano anterior não previa a articulação em torno da criação de um sistema, mesmo que tal demanda já fosse prevista anteriormente em outros dispositivos. Em contrapartida, na atual conjuntura há uma ampla discussão em torno da criação desse sistema, debate que vem sendo conduzido pela Secretaria de Articulação com os Sistemas de Ensino (SASE), vinculada ao MEC.

Oliveira (2011) apresenta em sua análise as implicações de um sistema educacional bem articulado para o avanço na superação de desigualdades e superação de disparidades entre os entes federados:

Por que o novo PNE deveria trazer em seu bojo o Sistema Nacional de Educação? A respos-
ta a essas indagações pode estar nos obstáculos que o regime federativo impõe à gestão e
organização da educação, na pouca integração revelada entre estados e municípios, na per-
sistência de desigualdades e desequilíbrios históricos entre regiões, na fragmentação entre
as redes públicas nos seus distintos níveis (municipais, estaduais e federal). (OLIVEIRA,
2011, p. 330)

O PNE prevê no artigo 13 a criação do Sistema Nacional de Educação (SNE), que, de acordo com o documento, será “[...] responsável pela articulação entre os sistemas de ensino, em regime de colaboração, para efetivação das diretrizes, metas e estratégias do Plano Nacional de Educação" (BRASIL, 2014a, art. 13). É dever do Poder Público instituir em lei específica o SNE, sendo estipulado o prazo de dois anos a contar da publicação do PNE.

De acordo com o próprio PNE, esse sistema englobaria o equilíbrio na repartição das responsabilidades e dos recursos da União, dos Estados, do Distrito Federal e dos Municípios. Segundo o artigo 214 da Constituição Federal, o PNE articularia o SNE em regime de colaboração de modo a assegurar as diretrizes e normas para a manutenção e o desenvolvimento do ensino (BRASIL, 1988).

Saviani (2014 b) apresenta a seguinte reflexão em torno do SNE:

Concebido na forma indicada e efetivamente implantado o Sistema, seu funcionamento será regulado pelo Plano Nacional de Educação. A ele cabe, a partir do diagnóstico da situação em que o Sistema opera, formular diretrizes, definir metas e indicar os meios pelos quais essas metas serão atingidas no período de vigência do plano definido pela nossa legislação em dez anos. (SAVIANI, 2014b, 32)

Do ponto de vista do autor, o PNE e o SNE devem estar articulados entre si, a partir do contexto de regulação do sistema nacional pelo plano. Ao problematizar questões em torno do SNE, Saviani (2014a) traz o seguinte questionamento: "Diante da reiterada resistência 
O Plano Nacional de Educação (2014-2024) e a garantia de um sistema educacional inclusivo: possibilidade ou utopia?

Samuel Vinente e Márcia Duarte

do Estado em assumir as responsabilidades financeiras na manutenção do ensino no país, como instituir o Sistema Nacional de Educação?" (SAVIANI, 2014a, p. 34).

O autor, ao tecer suas considerações, aponta para os obstáculos políticos presentes no cenário educacional brasileiro, tais como a descontinuidade nas políticas educativas, os obstáculos filosófico-ideológicos e os legais. Na mesma linha de raciocínio, Saviani (2014a) destaca o que ele intitula de perversa equação que ilustra a política educacional até os dias atuais, tal como pode ser observado no quadro 1:

Quadro 1 - Políticas educacionais no Brasil (Equação perversa)

Filantropia + Protelação + Fragmentação + Improvisação

$=$ Precarização geral do ensino no país

Fonte: Elaborado pelos autores a partir de Saviani (2014a, p. 40)

O quadro 1, ao ser analisado no âmbito da história da Educação Especial, não aponta resultados diferentes dos discutidos pelo autor. A descontinuidade de políticas, a fragmentação do AEE, no qual as salas de recursos multifuncionais tornam-se ambientes segregados, e a improvisação na formação de professores e na implementação das políticas de Educação Especial provocam a precarização do ensino, principalmente aos estudantes PAEE (KASSAR; ARRUDA; BENATTI, 2011; GARCIA; MICHELS, 2011; VINENTE et al., 2014; VINENTE; DUARTE, 2015).

Se a filantropia, a protelação, a fragmentação e a improvisação foram fatores para a exclusão e a precarização do ensino, torna-se necessário então construir caminhos distintos. Para a superação de tal fórmula é necessário que, além do estabelecimento do SNE, haja intensa avaliação e exaustivo monitoramento das políticas educacionais voltadas a este segmento populacional. Se isso for possível, "teremos, assim, um sistema único em todo o país assegurando a todos os brasileiros um mesmo tipo de educação" (SAVIANI, 2014, p. 60b).

\subsection{Análise dos indicadores educacionais do INEP}

Além de fomentar o debate em torno da criação e consolidação do SNE, torna-se indispensável também a análise e o monitoramento dos indicadores educacionais no tocante à matrícula de estudantes PAEE nos sistemas de ensino. $\mathrm{O}$ monitoramento dos dados referentes ao Censo Escolar da Educação Básica, que anualmente é realizado pelo Instituto Nacional de Estudos e Pesquisas Educacionais Anísio Teixeira (INEP), aponta um direcionamento para a tomada de decisões e possibilidades de avaliação do PNE.

O Censo Escolar baseia-se num "[...] levantamento de dados estatísticos educacionais de âmbito nacional realizado todos os anos e coordenado pelo Inep" (INEP, 2015, n.p.). De acordo com o Instituto, essas informações são utilizadas “[...] para traçar um 
O Plano Nacional de Educação (2014-2024) e a garantia de um sistema educacional inclusivo: possibilidade ou utopia?

panorama nacional da Educação Básica e servem de referência para a formulação de políticas públicas e execução de programas na área da educação [...]" (INEP, 2015, n.p.)

Os dados do INEP 2014, referentes ao Censo Escolar da Educação Básica 2013, apontam uma queda na matrícula de estudantes PAEE nas classes/escolas especiais e evidenciam um aumento significativo na matrícula desses estudantes nas classes comuns, no período de 2007 a 2013, como ilustra o gráfico 1:

Gráfico 1 - Número de Matrículas de estudantes Público-Alvo da Educação Especial no Brasil.

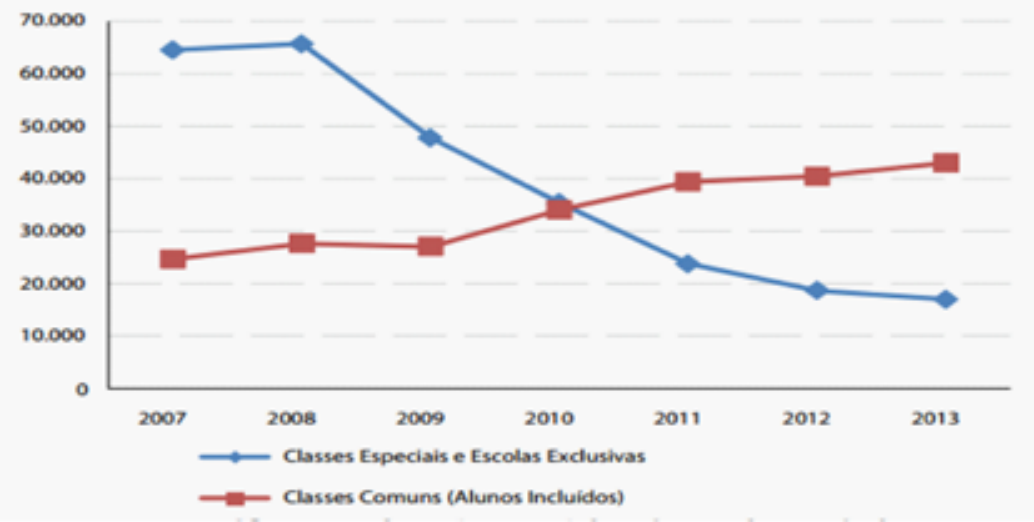

Fonte: Instituto Nacional de Estudos e Pesquisas Educacionais Anísio Teixeira (INEP, 2014)

Mesmo que os dados elencados no gráfico 1 tenham apontado um crescimento no contingente de matrículas nas classes comuns, não se pode afirmar que o acesso à escolarização vem se universalizando, tampouco que os estudantes das classes/escolas especiais estão todos migrando para as classes comuns (VINENTE; DUARTE, 2015).

A legislação ainda permite que o AEE seja ofertado tanto em salas de recursos multifuncionais, quanto em centros de AEE. Nessa perspectiva, a matrícula dos estudantes PAEE pode ser efetivada em instituições privadas sem fins lucrativos, especializadas e com atuação exclusiva em educação especial. Assim, é garantido no Decreto $\mathrm{n}^{0}$ 7.611/2011 o apoio técnico e financeiro do Poder Público às instituições supracitadas (BRASIL, 2011), diferentemente do previsto na Política Nacional de Educação Especial na Perspectiva da Educação Inclusiva (BRASIL, 2008).

É importante destacar que as matrículas de estudantes PAEE vêm crescendo tanto em escolas públicas quanto em particulares, no período de 2007 a 2013, como pode ser observado na tabela 1 (a seguir). Precisa-se, então, averiguar se ambos os sistemas de ensino estão preparados para atender a esses estudantes, no sentido de oferecer recursos pedagógicos, métodos e técnicas adequadas e acessibilidade curricular e arquitetônica. 
O Plano Nacional de Educação (2014-2024) e a garantia de um sistema educacional inclusivo: possibilidade ou utopia?

Samuel Vinente e Márcia Duarte

Tabela 1 - Número de Matrículas na Educação Especial por rede de ensino

\begin{tabular}{|c|c|c|}
\hline Ano & Matrículas nas escolas públicas & Matrículas nas escolas particulares \\
\hline 2007 & 410.281 & 244.325 \\
\hline 2009 & 454.927 & 184.791 \\
\hline 2011 & 588.896 & 163.409 \\
\hline 2013 & 664.466 & 178.876 \\
\hline
\end{tabular}

Fonte: Instituto Nacional de Estudos e Pesquisas Educacionais Anísio Teixeira (INEP, 2014).

Nota-se que, se a matrícula na rede particular diminui entre 2007 e 2011, ela cresceu entre 2011 e 2013. Já na rede pública, como se pode verificar na tabela 1, a matrícula cresceu tanto entre 2007 e 2009, quanto em 2011 e 2013, ou seja, está em crescente ascensão.

No tocante à intersetorização das políticas públicas para o acompanhamento desse público-alvo, a estratégia 4.9 contida no PNE prevê a colaboração, o acompanhamento e o monitoramento por meio de programas sociais, pretendendo-se fortalecer acesso à escola e ao AEE, bem como a permanência e o desenvolvimento acadêmico dos estudantes PAEE beneficiários de programas de transferência de renda, em colaboração com as famílias e com os órgãos públicos de assistência social, saúde e proteção à infância, à adolescência e à juventude (BRASIL, 2014a).

Outra estratégia contida no PNE diz respeito à garantia do atendimento escolar integral aos educandos PAEE dos quatro aos dezessete anos, podendo ser oferecido na própria escola ou em instituições especializadas. É importante destacar que nos casos em que o estudante frequenta a escola em um turno e no outro participa do AEE, o estudante já possui um tempo mais amplo de permanência na escola. Entretanto, a leitura do texto permite diversas interpretações, pois o atendimento garantido pode basear-se na progressão do tempo de permanência na escola/instituição e na prestação de diversos serviços e oportunidades que possam garantir o desenvolvimento integral dos estudantes PAEE.

Por intermédio do PNE garante-se que o Poder Público deve assegurar aos estudantes o AEE ofertado na mesma escola onde estudam ou em instituições especializadas próximas de suas residências. Sabe-se que cada município implementa a oferta do AEE de formas distintas. Sendo assim, seria necessário um planejamento quanto aos locais propícios para o AEE e a articulação com a educação em tempo integral.

Os indicadores educacionais, ao serem monitorados, podem sinalizar aspectos positivos ou negativos referentes à implementação das políticas educacionais. Os dados do estudo vêm apontando um investimento da esfera governamental no atendimento aos educandos caracterizados como PAEE, no entanto, isso ainda ocorre a passos lentos. Os dados do Censo Escolar do INEP 2014 apontam um crescimento no número de alunos matriculados em classes regulares nas diferentes etapas e modalidades de ensino, como pode ser observado na tabela 2 : 
O Plano Nacional de Educação (2014-2024) e a garantia de um sistema educacional inclusivo: possibilidade ou utopia?

Samuel Vinente e Márcia Duarte

Tabela 2 - Número de alunos incluídos em classes comuns no Brasil (2007-2013)

\begin{tabular}{|c|c|c|c|c|c|c|}
\hline Ano & Ed. Infantil & Ens. Funda. & Ens. Médio & EJA & Ed. Profissional & Total \\
\hline 2007 & 24.634 & 239.506 & 13.306 & 28.295 & 385 & 306.136 \\
\hline 2008 & 27.603 & 297.986 & 17.344 & 32.296 & 546 & 375.775 \\
\hline 2009 & 27.031 & 303.383 & 21.465 & 34.434 & 718 & 387.031 \\
\hline 2010 & 34.044 & 380.112 & 27.695 & 41.385 & 1.096 & 484.332 \\
\hline 2011 & 39.367 & 437.132 & 33.138 & 47.425 & 1.361 & 558.423 \\
\hline 2012 & 40.456 & 485.965 & 42.499 & 50.198 & 1.659 & 620.777 \\
\hline 2013 & 42.982 & 505.505 & 47.356 & 51.074 & 2.004 & 648.921 \\
\hline
\end{tabular}

Fonte: Instituto Nacional de Estudos e Pesquisas Educacionais Anísio Teixeira (2014)

Conforme pode ser observado na tabela 2 , os dados do INEP contabilizaram apenas o número de alunos incluídos nas classes comuns, não computando o número de alunos matriculados em turmas de atendimento complementar ou salas de AEE. Observa-se que de 2007 a 2013 houve elevado crescimento nas matrículas em salas comuns, levando-se em consideração que os sistemas de ensino adotaram a política do MEC referente à implantação de salas de recursos multifuncionais (BRASIL, 2008), como pode ser visto em outros trabalhos (KASSAR; ARRUDA; BENATTI, 2011; BUENO; MELETTI, 2012; VINENTE, OLIVEIRA, 2014; VINENTE et al., 2014).

Com o aumento da matrícula de estudantes PAEE nas classes de ensino regulares, logicamente deveria crescer também a demanda de salas de recursos multifuncionais, de recursos pedagógicos, de professores qualificados para atuação no AEE e da adequação do mobiliário e infraestrutura da escola.

O PNE em vigência prevê a publicação de estudos realizados pelo INEP de dois em dois anos, com vistas à evolução no cumprimento das metas estabelecidas na lei (BRASIL, 2014a). No tocante à meta 4 , escopo de análise deste texto, a lei prevê a definição de "[...] indicadores de qualidade e política de avaliação e supervisão para o funcionamento de instituições públicas e privadas [...]" que prestam o AEE (BRASIL, 2014a, n.p.). Nessa perspectiva, torna-se necessário que as pesquisas se debrucem ao analisar tais indicadores e contribuam com a avaliação do PNE enquanto política pública para os estudantes PAEE.

\subsection{Avaliação e monitoramento dos planos estaduais e municipais de educação}

Ratificando o que já era disposto na Constituição Federal (BRASIL, 1988), na Lei de Diretrizes e Bases (BRASIL, 1996) e no Plano Nacional anterior (BRASIL, 2001), o PNE vigente normatiza que os sistemas de ensino do Distrito Federal, dos Estados e Municípios devem criar mecanismos para o monitoramento da consecução local do PNE. Além disso, os entes federados elaborariam seus planos educacionais em consonância com o documento vigente. 
O Plano Nacional de Educação (2014-2024) e a garantia de um sistema educacional inclusivo: possibilidade ou utopia?

Samuel Vinente e Márcia Duarte

O PNE prevê em seu artigo $8^{\circ}$ que "Os Estados, o Distrito Federal e os Municípios deverão elaborar seus correspondentes planos de educação, ou adequar os planos já aprovados em lei, em consonância com as diretrizes, metas e estratégias previstas neste PNE [...]" (BRASIL, 2014a, art. 8º. A lei obriga que esses planos sejam aprovados no período de um ano a partir da publicação da lei no Diário Oficial da União.

Segundo dados atuais do MEC (2015), aproximadamente 98\% dos municípios já elaboraram seus planos de educação, estando prontos a serem aprovados nas Câmaras Municipais. Um ano após a promulgação da Lei que dispõe sobre o atual PNE, 5.438 municípios já estavam com os planos elaborados em apreciação nas instâncias deliberativas, e destes 4.710 já haviam obtido a aprovação (MEC, 2015).

O Documento Orientador Planejando a próxima década: alinhando os planos de educação (BRASIL, 2014 b), lançado pela Secretaria de Articulação com os Sistemas de Ensino (SASE), vinculada ao MEC, traz orientações para que os sistemas de ensino se organizem para a elaboração dos planos estaduais e municipais. De acordo com o documento, "a participação no processo decisório é um dos meios de fortalecimento e ampliação do espaço público, que poderá permitir o redirecionamento ou a reconstrução das prioridades das políticas públicas na direção do atendimento aos interesses da maioria" (BRASIL, 2014b, p. 8).

A possibilidade dos Estados, Municípios e do Distrito Federal elaborarem seus próprios planos permite que os mesmos dialoguem com a sociedade e estabeleçam metas específicas, de acordo com o contexto histórico, social e político do lugar. Ao avaliar o cumprimento das estratégias e metas do PNE anterior, Aguiar (2010) aponta para a necessidade de intensa articulação entre os entes federados:

A avaliação do PNE evidencia que a ausência de cumprimento das metas não pode ser atribuída apenas à instância da União. Esta tem responsabilidades concretas, mas os estados, o Distrito Federal e os municípios são corresponsáveis pelos compromissos do Plano. Dependendo da forma como se efetivam as relações entre os entes federados, dos arranjos institucionais e das condições políticas existentes, as metas poderão ser ou não alcançadas. (AGUIAR, 2010, p. 724)

Os entes federados podem fomentar diversas ações para alcançar até o fim da década a universalização do ensino, principalmente o ingresso e a permanência dos educandos PAEE na Educação Básica e Superior. Vale salientar que isso não é uma tarefa fácil mas, com investimentos e a inserção da educação na agenda do Poder Público, podem-se operacionalizar mudanças significativas (VINENTE; DUARTE, 2015).

Ao mesmo tempo em que o plano prevê a intensa mobilização da sociedade na elaboração dos planos municipais e estaduais, entende-se que a velocidade em que as discussões ocorrem pode variar de acordo com os diferentes contextos. Torna-se necessário que os profissionais da educação se articulem na mobilização de diretrizes que condizem com as especificidades de cada município. Levando-se em consideração que os diversos Estados e Municípios brasileiros possuem especificidades na arrecadação de impostos 
O Plano Nacional de Educação (2014-2024) e a garantia de um sistema educacional inclusivo: possibilidade ou utopia?

Samuel Vinente e Márcia Duarte

e na receita vinculada à educação, acredita-se que o regime de colaboração constituído pelo SNE poderia contribuir para minimizar parte dos problemas educacionais.

No contexto de elaboração de planos que tragam respostas aos problemas educacionais, Estados e Municípios devem observar as diretrizes da CF, principalmente no que diz respeito ao financiamento da educação. Nessa perspectiva, a União não deve gastar menos de 18\% de sua receita e os Estados, o Distrito Federal e os Municípios menos que 25 de sua receita com a educação (BRASIL, 1988).

É importante que os planos contemplem a questão do financiamento projetado para a década e norteiem os investimentos a serem realizados nos distintos sistemas de ensino para que todos os estudantes sejam atendidos em suas especificidades.

\section{Considerações Finais}

É inegável que nos últimos anos houve muitos avanços nas práticas escolares e também nos dispositivos jurídico-legais relativos ao AEE. Os indicadores educacionais do INEP têm apontado um panorama em que, ao mesmo tempo em que mais estudantes estão matriculados nos sistemas de ensino, torna-se necessário também assegurar meios para que permaneçam e obtenham sucesso na trajetória escolar. Os indicadores fornecidos devem ser avaliados e monitorados pela sociedade, de modo que possibilitem apontar um panorama sobre a efetivação de um sistema educacional inclusivo.

Outro desafio no contexto atual refere-se ao rompimento das desigualdades educacionais, sociais e econômicas presentes nas diferentes regiões do país. Uma política nacional precisa levar em consideração o orçamento dos Municípios, dos Estados e a possibilidade de apoio técnico e financeiro da União. Para isso, faz-se importante a discussão sobre a regulamentação do SNE e sua implementação com vistas à operacionalização do PNE em regime de colaboração.

Sabe-se que o estudo não se encerra, pois há necessidade de mais pesquisas nas diferentes regiões do Brasil para a avaliação da execução do PNE, bem como no monitoramento da elaboração e implantação dos planos municipais e estaduais de educação. Nessa perspectiva, acreditamos que o trabalho possibilitará aos pesquisadores da área a sinalização de lacunas a serem preenchidas no campo da Educação Especial e das políticas de inclusão escolar nos próximos anos.

Nesse contexto, os educadores e pesquisadores das diferentes regiões precisam unir esforços para que os resultados de suas pesquisas sejam ouvidos não somente nos fóruns de discussões educacionais, mas possam também auxiliar o Poder Público na formulação e implementação de políticas que atendam às especificidades dos estudantes PAEE e dos demais segmentos educacionais que congregam a diversidade tão presente no cotidiano escolar.

Faz-se mister que o PNE, enquanto política pública educacional e social, não se torne apenas utopia mas concretize-se enquanto realidade presente no cotidiano das escolas 
O Plano Nacional de Educação (2014-2024) e a garantia de um sistema educacional inclusivo: possibilidade ou utopia?

brasileiras. Portanto, o grande desafio dos pesquisadores e profissionais da educação que se debruçam no campo das políticas públicas é não somente questionar as demandas da legislação atual para a escolarização destes estudantes, mas problematizar no sentido de que os discursos devem garantir e reconhecer as conquistas históricas dos movimentos sociais e dos direitos humanos, e precisam ser efetivados.

\section{Referências Bibliográficas}

AGUIAR, M. A. S. Avaliação do Plano Nacional de Educação 2001-2009: questões para reflexão. Educação e Sociedade, Campinas, v. 31, n. 112, p. 707-727, jul./set. 2010.

BRASIL. Constituição Federal de 1988. Disponível em: <www.planalto.gov.br> Acesso em: 13 abr. 2015.

BRASIL. Decreto $\mathbf{n}^{\mathbf{0}}$ 7.611, de 17 de novembro de 2011: dispõe sobre a Educação Especial, o atendimento educacional especializado e dá outras providências. Disponível em: <http://www.planalto.gov.br>. Acesso em 05 jan. 2015.

BRASIL. Emenda Constitucional no 59, de 11 de novembro de 2009. Brasília: DF, 2009. Disponível em: <http://www.planalto.gov.br >. Acesso em 20 mar. 2015.

BRASIL. Lei no 10.172, de 9 de janeiro de 2001: aprova o Plano Nacional de Educação e dá outras providências. Disponível em: <www.planalto.gov.br>. Acesso em 29 mar. 2015.

BRASIL. Lei n 13.005, de 25 de junho de 2014: aprova o Plano Nacional de Educação - PNE e dá outras providências. Disponível em: <www.planalto.gov.br $>$. Acesso em: 06 dez. 2014a.

BRASIL. Lei no 5.692, de 11 de agosto de 1971: fixa as diretrizes e bases para o ensino de $1^{\circ}$ e $2^{\circ}$ graus, e dá outras providências. Disponível em: <www.planalto.com.br>. Acesso em: 03 ago. 2015.

BRASIL. Lei no 9.394, de 20 de dezembro de 1996: estabelece as diretrizes e bases da educação nacional. Disponível em: < http://www.planalto.gov.br >. Acesso em: 09 set. 2014.

BRASIL. Nota Técnica $\mathbf{n}^{\mathbf{0}}$ 108, de 21 de agosto de 2013: sobre a redação da meta 4 do PNE. Brasília: MEC/SECADI/DPEE, 2013.

BRASIL. Planejando a próxima década: alinhando os planos de educação. Brasília: Secretaria de Articulação com os Sistemas de Ensino - SASE, 2014 b.

BRASIL. Política Nacional de Educação Especial na Perspectiva da Educação Inclusiva. Brasília: MEC/SEESP, 2008. 
O Plano Nacional de Educação (2014-2024) e a garantia de um sistema educacional inclusivo: possibilidade ou utopia?

Samuel Vinente e Márcia Duarte

BUENO, J. G. S.; MELETTI, S. M. F. Políticas de escolarização de alunos com deficiência: análise das atuais políticas e dos indicadores sociais da educação escolar. In: MENDES, E. G.; ALMEIDA, M. A. A pesquisa sobre inclusão escolar em suas múltiplas dimensões: teoria, política e formação. Marília: ABPEE, 2012. p. 127-146.

CURY, C. R. J. A educação básica no Brasil. Educação e Sociedade, Campinas, v. 23, n. 80 , p. $168-200$, set. 2002.

CURY, C. R. J. Os fora de série na escola. Campinas, SP: Autores Associados, 2005.

DOURADO, L. F. Políticas e gestão da educação básica no Brasil: limites e perspectivas. Educação e Sociedade, Campinas, v.28, n.100, p. 921-946, 2007.

DOURADO, L. F.; OLIVEIRA, J. F. A qualidade da educação: perspectivas e desafios. Cadernos CEDES, Campinas, v.29, n.78, p. 201-215, 2009.

GARCIA, R. M. C.; MICHELS, M. H. A política de educação especial no Brasil (19912011): uma análise da produção do GT15 - educação especial da ANPED. Revista Brasileira de Educação Especial, Marília, v. 17, n.1, p. 105-124, 2011.

GIL, A. C. Como elaborar projetos de pesquisa. 4. ed. São Paulo: Atlas, 2008.

INEP. Censo Escolar da Educação Básica (2013): Resumo Técnico. Ministério da Educação. Brasília: INEP, 2014.

INEP. Censo Escolar: o que é o Censo Escolar? Disponível em: $<\underline{\text { http://portal.inep.gov. }}$ br/basica-censo >. Acesso em: 04 jul. 2015.

KASSAR, M. C. M.; ARRUDA, E. E.; BENATTI, M. M. S. Políticas de inclusão: o verso e o reverso de discursos e práticas. In: JESUS, D. M.; BAPTISTA, C. R.; BARRETO, M. A. S. C. (Orgs.). Inclusão, práticas pedagógicas e trajetórias de pesquisa. 3. ed. Porto Alegre: Mediação, 2011. p. 21-31.

LAPLANE, A. L. F; PRIETO, R. G. Inclusão, diversidade e igualdade na CONAE 2010: perspectivas para o novo Plano Nacional de Educação. Educação e Sociedade, Campinas, v. 31, n. 112, p. 919-938, jul./set. 2010.

MEC. Para ministro, sociedade assumiu o plano e os municípios estão cumprindo o seu papel. Disponível em: <portal.mec.gov.br/index.php?option=com content \&view=article\&id=21456:para-ministro-sociedade-assumiu-o-plano-e-municipios-estao-cumprindo-o-seu-papel-\&catid=211\&Itemid=86>. Acesso em: 02 ago. 2015.

MENDES, E. G. A radicalização do debate sobre inclusão escolar no Brasil. Revista Brasileira de Educação, Rio de Janeiro, v. 11, n.33, 2006. p. 387-405. 
O Plano Nacional de Educação (2014-2024) e a garantia de um sistema educacional inclusivo: possibilidade ou utopia?

OLIVEIRA, D. A. Das políticas de governo às políticas de estado: reflexões sobre a atual agenda educacional brasileira. Educação e Sociedade, Campinas, v. 32, n. 115, p. 323-337, abr./jun. 2011.

OLIVEIRA, D. A. et al. Por um Plano Nacional de Educação (2011-2020) como política de Estado. Revista Brasileira de Educação, Rio de Janeiro, v. 16, n. 47, p. 483-492, mai./ago. 2011.

SAVIANI, D. Educação brasileira: estrutura e sistema. 11. ed. Campinas, SP: Autores Associados, 2012.

SAVIANI, D. Sistema Nacional de Educação e Plano Nacional de Educação: significado, controvérsias e perspectivas. Campinas, SP: Autores Associados, 2014a.

SAVIANI, D. O Manifesto dos Pioneiros da Educação Nova de 1932 e a questão do Sistema Nacional de Educação. In: CUNHA, Célio da et al. O Sistema Nacional de Educação: diversos olhares 80 anos após o Manifesto. Brasília: MEC/SASE, 2014b. p. 15-29.

VINENTE, S. et al. A construção do conceito de inclusão no Brasil: um olhar para as políticas públicas. In: CONGRESSO BRASILEIRO DE EDUCAÇÃO ESPECIAL, 6 ., 2014, São Carlos. Anais... São Carlos: Universidade Federal de São Carlos, 2014. p. 1-15.

VINENTE, S.; DUARTE, M. Demandas do atual Plano Nacional de Educação para o Atendimento Educacional Especializado. In: CONGRESSO INTERNACIONAL DE EDUCAÇÃO, 6., 2015, Santa Maria. Anais... Santa Maria: FAPAS, 2015. p. 1-12.

VINENTE, S.; OLIVEIRA, S. S. B. Implantação das salas de recursos multifuncionais no Brasil: avaliação de um programa. In: CONGRESSO BRASILEIRO DE EDUCAÇÃO ESPECIAL, 6., 2014, São Carlos. Anais... São Carlos: Universidade Federal de São Carlos, 2014. p. 1-10.

Recebido em: 06/08/2015

Aprovado em: 21/10/2015 